\title{
SPATIAL AND TEMPORAL EVOLUTION CHARACTERISTICS OF DROUGHT-FLOOD ABRUPT ALTERNATION IN GUIZHOU PROVINCE IN RECENT 50 YEARS BASED ON DWAAI INDEX
}

\author{
FAN, H. ${ }^{1}-$ ZHANG, Z. Z. ${ }^{1}-$ WU, F. ${ }^{1 *}-$ XU, J. X. ${ }^{1}-$ SHEN, D. F. ${ }^{2}-$ YUAN, Y. J. ${ }^{1}$ \\ ${ }^{I}$ School of Water Conservancy, North China University of Water Resources and Electric Power \\ Zhengzhou 450011, China \\ ${ }^{2}$ Guizhou Water Conservation Science and Research Institute, Guiyang 550002, China \\ ${ }^{*}$ Corresponding author \\ e-mail:36560797@qq.com
}

(Received $3^{\text {rd }}$ May 2019; accepted $11^{\text {th }}$ Jul 2019)

\begin{abstract}
Based on the daily rainfall data of 19 meteorological stations in Guizhou Province from 1968 to 2017 and combining the characteristic of hydrogeology in Guizhou Province, this study revised the Dry-Wet Abrupt Alternation Index (DWAAI) and analyzed the spatial and temporal evolution characteristics of drought-flood abrupt alternation in Guizhou Province in recent 50 years. The results show that: 1. the revised DWAAI index has good applicability in Guizhou Province; 2) The time of drought-flood abrupt alternation is mainly distributed from April to October. In terms of the interannual variation, the station proportion and intensity show an increasing trend, and the increasing trend was significant in station proportion. The intensity of drought-flood abrupt alternation in autumn shows a decreasing trend, and the station proportion and intensity increase in other seasons, in which the intensity of the drought-flood abrupt alternation in spring and summer and the station proportion of the droughtflood abrupt alternation in summer increase significantly. (3) The frequency of the drought-flood abrupt alternation in Guizhou Province decreased from east to west as a whole. It is easy to occur in spring in the south, in summer in the middle and the north with the largest area, and in autumn in the east. With the increase of the years, the scope of prone areas has been expanding. The results are of great significance for disaster prediction and early warning and drought and flood control in this area.
\end{abstract}

Keywords: drought and flood, revised index, trend analysis, spatial analysis

\section{Introduction}

Guizhou is a province with frequent natural disasters, mainly including flood and drought disasters, low-temperature freezing, wind and hail, landslide and debris flow, among which the occurrence frequency of flood and drought disasters is higher, with the larger disaster area, which mostly appear as flower arrangement, so it is easy to form drought-flood abrupt alternation events and pose a serious threat to the local social and economic development. The drought-flood abrupt alternation refers to the meteorological and hydrological events such as floods when there is no precipitation or little precipitation in the early stage and the drought has occurred, and then highintensity precipitation occurs in a short period of time (Huang, 2015). The droughtflood abrupt alternation usually coincides with the growth period of autumn harvest and summer harvest crops, encounters the abrupt alteration of drought and flood disasters in a short period, the influence and loss of the region is multiplied, and climate change leads to the increase of extreme hydrological events, which increases the risk of drought-flood abrupt alternation to a large extent. Many scholars in China and abroad studied flood and drought disasters from the aspects of forming factors (Djebou et al., 2014), physical processes (Langousis and Kaleris, 2014; Goswami et al., 2018) and 
evolution rules (Grinsted et al., 2014; Andrea et al., 2018), but most of them focused on relatively independent elements such as "flood" and "drought" (Zhou et al., 2013; Han et al., 2014; Liu et al., 2014; Rajsekhar et al., 2015) or uses drought-flood abrupt alternation as a fixed element. With the intensification of climate change, especially the frequent and wide occurrence of drought and flood events in China, the study of "flood" and "drought" coupling has entered into a development period in China. Many scholars used conventional meteorological dry and wet indicators such as continuous rain-free days (Cheng et al., 2012), precipitation anomaly (Shen et al., 2012) and SPI (Wu et al., 2006a,b) to study the drought-flood abrupt alternation, with good results in macroscopic law recognition and characteristic analysis, but failing to completely describe the process and intensity of the drought-flood abrupt alternation. For better quantify, Wu et al. (2006b) compared the differences in precipitation between May-June and JulyAugust, and defined a Long-cycle Drought-Flood Abrupt Alternation Index (LDFAI); Zhang et al. (2012) referred to LDFAI, and defined the Runoff Drought-Flood Abrupt Alternation Index (RDFAI); Shan et al. (2018) improved the problem of large time scale of LDFAI index and constructed the Dry-Wet Abrupt Alteration Index (DWAAI), which not only reflects the difference of drought and flood in the former and later stages, but also reflects the degree of urgency from drought to flood, that's, it can comprehensively reflect the "abrupt" and "alternation" of the drought-to-flood.

Based on DWAAI and combining with the characteristics of hydrology, meteorology, soil and geology in Guizhou Province, this study revised the degree of drought and flood in the former and later stages of the index. Based on the calculated results, the temporal and spatial evolution characteristics and regularities of drought-flood abrupt alternation events in Guizhou Province are analyzed by using climatic tendency rate, Mann-Kendall method and Inverse Distance Weighting (IDW). The purpose of the study is to monitor and warn drought-flood abrupt alternation disasters, formulate comprehensive response plans for the sudden disasters of drought-flood abrupt alternation, reduce disaster losses, and provide scientific support for agricultural production safety in this region.

\section{Materials and methods}

\section{Overview of the research area}

Guizhou Province belongs to the Yangtze River Basin and the Pearl River Basin, and its geographical position is between $103^{\circ} 36^{\prime} \mathrm{E}-109^{\circ} 35^{\prime} \mathrm{E}$ and $24^{\circ} 37^{\prime} \mathrm{N}-29^{\circ} 13^{\prime} \mathrm{N}$. The territory is high in the west and low in the east, sloping northward, eastward and southward from the middle, with an average elevation of about $1,000 \mathrm{~m}$ above sea level and over 1,600-2,800 $\mathrm{m}$ above sea level in the west. The river network of the whole province is dense, the river slope is steep, the landform is complex and diverse, mainly with mountainous and hilly areas, and the karst landform is widely distributed, accounting for about $73 \%$ of the total area of the province. Guizhou Province belongs to the sub-tropical temperate and humid monsoon climate region. The basic meteorological data of 19 meteorological stations in the province over the past 50 years have been collated and counted,and the annual average temperature is about $15^{\circ} \mathrm{C}$ and rain and heat are in the same season, with the annual rainfall of $1,179 \mathrm{~mm}$ but the uneven spatial and temporal distribution, descending from southeast to northwest. The annual rainfall from May to October accounts for $75 \%$ of the total. 


\section{Data sources}

The data of this study are obtained from the National Meteorological Information Center of China Meteorological Administration (http://data.cma.cn), using daily rainfall data of 19 basic meteorological stations in Guizhou Province from 1968 to 2017 to sort and make up the difference in the quality of the original data. See Figure 1 for spatial distribution of meteorological stations.

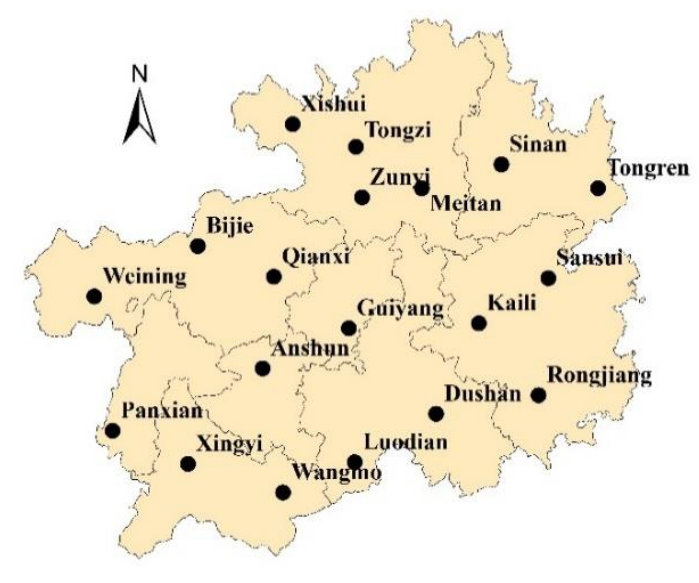

- Meteorological stations

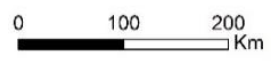

Figure 1. Distribution of meteorological stations in Guizhou province

\section{Indicators and methods}

Revised DWAAI index

(1) DWAAI index

The DWAAI index calculation model is derived from the LDFAI defined by $\mathrm{Wu}$ et al (2006b). The LDFAI index was improved by Shan et al. (2018) to construct the DWAAI index, with equation as follows:

$$
\begin{gathered}
D W A A I_{i}=\left[K+\left(S P A_{a i}-S P A_{c a i}\right) \times\left(\left|S P A_{c a}\right|+\left|S P A_{a i}\right|\right)\right] \times a^{-\left|S P A_{e a} i+S P A_{a l i}\right|} \\
K=\sum_{i=1}^{n}\left(\frac{S A P I_{i}-S A P I_{0}}{i}\right)
\end{gathered}
$$

In Equation (1), $S P A_{\text {ea } i}$ and $S P A_{\text {la }}$ represent the anomalies of normalized precipitation in the early and late periods (Maheras et al., 1999); in Equation (2), SAPI $I_{i}$ and $S A P I_{0}$ represent the value of the Standard Antecedent Precipitation Index (SAPI) in the $i$-th day and the antecedent last day of the flood period, which is calculated with the standardization of Antecedent Precipitation Index (API); $\mathrm{n}$ represents days in flood period; $a$ represents weight coefficient, with the value range of $1<a \leq 1.4$ as recommended by Literature (Shan et al., 2018), and $a=1.1$ according to the actual situation of Guizhou and the comparison and rationality analysis of various calculation results. 
(2) DWAAI index revision

In the drought-flood abrupt alternation events, the formation of drought in the early stage and drought-flood abrupt alternation in the late stage are two different stages, with different mechanisms. The formation of drought is the result of drought accumulation in the early stage, and the influence of daily precipitation on drought in the early stage decreases exponentially with the increase of drought date ( $\mathrm{Lu}, 2009)$; floods caused by late heavy rainfall have short-term characteristics, and there is no attenuation and accumulation process. Therefore, this study revise $S P A_{\text {ea } i}$ and $S P A_{\text {la } i}$ as follows:

$$
\begin{aligned}
& S P A_{\text {ca } i}=\sum_{j=0}^{m} k^{j} S P A_{-j} \quad(i \geq 45 \text { and } i, j \in N) \\
& S P A_{\text {qa }_{i}}=\frac{1}{n} \sum_{j=1}^{n} S P A_{i_{+j}}(i \geq 1 \text { and } i, j \in N)
\end{aligned}
$$

In Equation (3), m represents the number of drought days, and the influence of the 44th day in the early stage on the drought is less than $1 \%$, so m takes 44 herein; $\mathrm{k}$ represents the attenuation index; Lu (2009) recommends $\mathrm{k}$ as 0.9 in the study of the Mississippi Valley. But Guizhou Province is of mainly karst landform, mountainous and hilly, the soil thickness is thin and the groundwater layer is deep, so the attenuation degree is larger. Combined with the actual parameter optimization, $\mathrm{k}=0.87$ is selected in this study. In Equation (4), n represents the days of flood period, because of the short-term nature of flood and flood, the excessively large value of $n$ will cause "drought and flood neutralization". Combined with the meteorological characteristics of Guizhou Province and the actual calculation results, $n=5$ in this study. According to the calculation results and the actual situation of Guizhou, the classification of droughtflood abrupt alternation grade based on DWAAI index is shown in Table 1.

Table 1. Grade division of drought-flood abrupt alternation

\begin{tabular}{c|c|c|c|c}
\hline Grade & None & Light & Moderate & Heavy \\
\hline Value range of DWAAI & $(0,12.0)$ & {$[12.0,18.0)$} & {$[18.0,25.0)$} & {$[25.0, \infty)$} \\
\hline
\end{tabular}

\section{Research methods}

Referring to the regional drought assessment index constructed by Huang et al. (2010), this study uses frequency, station proportion and intensity of drought-flood abrupt alternation to reflect the spatial and temporal characteristics of drought-flood abrupt alternation events in Guizhou Province, among which station proportion reflects the range of drought-flood abrupt alternation events with equation as follows:

$$
P=\frac{m}{M} \times 100 \%
$$

In Equation (5), $\mathrm{P}$ represents station proportion; m represents the number of the meteorological stations which occurred drought-flood abrupt alternation event in study 
area; $M$ represents the number of all the meteorological stations in study area. It indicates the scope of drought-flood abrupt alternation in a certain region.

The climate tendency rate and Mann-Kendall method are used to analyze the trend. The climate tendency rate is linear tendency rate. The least square method is used to fit the unitary regression equation of the long-time element sequence, which is expressed as 10 times of the regression coefficient. Mann-Kendall method is used to test the significance of the trend. ArcGIS Inverse Distance Weighting (IDW) method is used to analyze spatial evolution characteristics.

\section{Results}

\section{Verification of indicator applicability}

At present, the research on the drought-flood abrupt alternation in China is mainly concentrated in the middle and lower reaches of the Yangtze River and the Huaihe River Basin while the characteristics and types of rainfall, drought and flood in Guizhou Province are different from those in the above areas. Therefore, this study takes the typical drought and flood abrupt alternation events in 2011 and 2012 as examples to verify the applicability of the revised DWAAI index in Guizhou Province. According to the calculation results, the spatial distribution of drought-flood abrupt alternation events in Guizhou Province in 2011 and 2012 is shown in Figure 2.

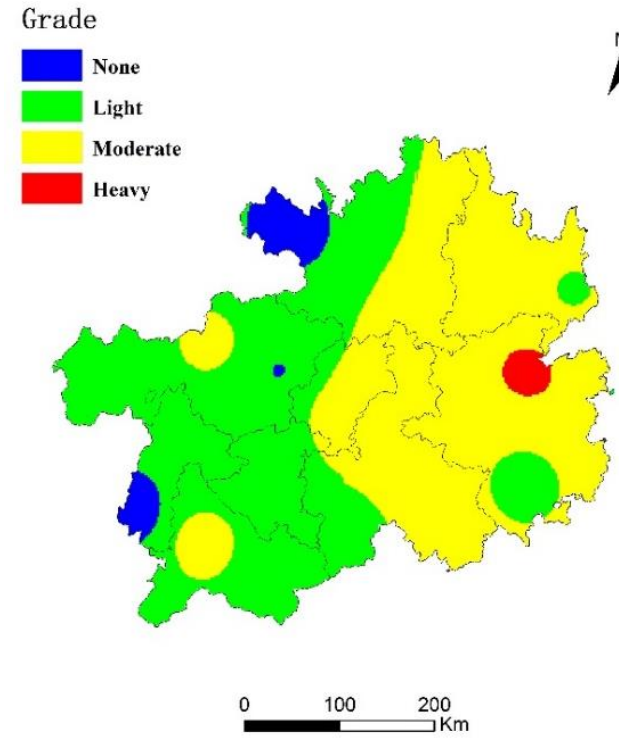

(a) 2011

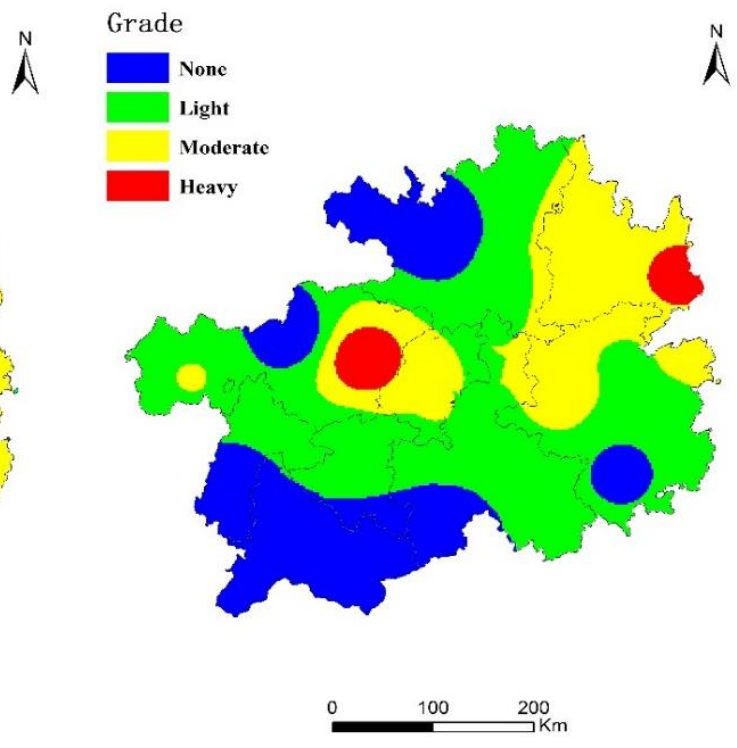

(b) 2012

Figure 2. Spatial distribution of drought-flood abrupt alternation events in 2011 and 2012 in Guizhou province

According to the actual situation, in the middle and upper part of June 2011, there was a strong precipitation process in the northern-central Jiangxi, the central Hunan and the eastern Guizhou. Although the drought was alleviated, the drought-flood abrupt alternation occurred in some areas of the three provinces. In late May 2012, due to uneven distribution of rainfall, serious drought-flood abrupt alternation occurred in 
Yanhe County and Dejiang County of Tongren City and Qianxi County of Bijie City. As can be seen from Figure 2a, in 2011, except for a few areas such as the west of Zunyi City and the southwest of Liupanshui City, most regions of Guizhou Province experienced drought-flood abrupt alternation in different degrees, with the most serious in the east. As can be seen from Figure 2b, in 2012, except for the southern and northwest regions of Guizhou Province, the drought-flood abrupt alternation occurred in different degrees in other regions, and the high-intensity regions are consistent with the historical reality.

Combining with the actual situation of the drought-flood abrupt alternation in Guizhou Province from 2011 to 2012, this paper selected data of the rainfall process and the corresponding DWAAI indices before and after the occurrence of drought-flood abrupt alternation happened in Rongjiang County in 2011, and in Qianxi County and Tongren City in 2012, as shown in Figure 3.
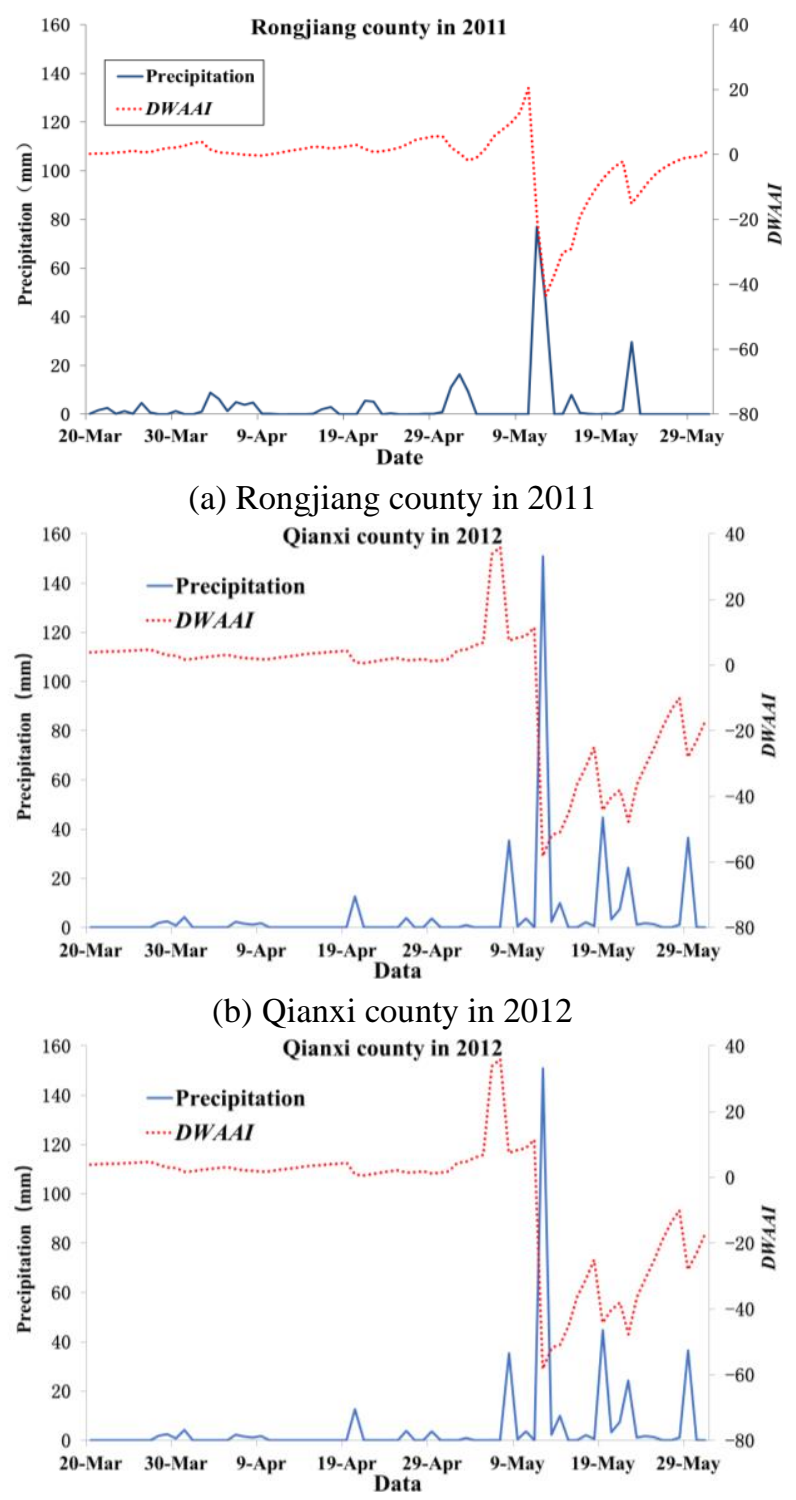

(c) Tongren city in 2012

Figure 3. The process of typical drought-flood abrupt alternation events in 2011 and 2012 in Guizhou province 
From Figure $3 a$ we can see that, in the Rongjiang County, the accumulated precipitation in 45 days before May $10^{\text {th }} 2011$ was $87.5 \mathrm{~mm}$, and the accumulated precipitation in 5 days after May $10^{\text {th }}$ was $132.2 \mathrm{~mm}$, wherein the single-day precipitation on May $11^{\text {th }}$ was $77 \mathrm{~mm}$, and the DWAAI of May $10^{\text {th }}$ was 20.5 , which had reached an extremum, so the May $10^{\text {th }}$ had been determined as the date of the drought-flood abrupt alternation occurrence, with a degree of moderate; moreover, from Figure $3 b$ we can see that, in the Qianxi County, the accumulated precipitation in 45 days before May $7^{\text {th }} 2011$ was $35.3 \mathrm{~mm}$, and the accumulated precipitation in 5 days after May $7^{\text {th }}$ was $190.5 \mathrm{~mm}$, although the single-day precipitation reached $150.9 \mathrm{~mm}$ on May $12^{\text {th }}$, the DWAAI extreme value 35.9 appeared on May $7^{\text {th }}$ with a degree of severe, this is because the single-day precipitation on May $8^{\text {th }}$ was $35.4 \mathrm{~mm}$, which can better reflect the "abrupt" degree of the change of drought and flood since that day, therefore, the May $7^{\text {th }}$ had been determined as the date of the drought-flood abrupt alternation occurrence, and after a certain period of flood season, the drought-flood abrupt alternation had produce serious impact in mid- and late-May; similarly, as can be seen from Figure 3c, Tongren City had determined the May $8^{\text {th }}$ as the date of the drought and flood abrupt alternation occurrence, but its DWAAI was 15.4, indicating it was a slight degree drought-flood abrupt alternation. This is because the accumulated precipitation in the previous period reached $204.9 \mathrm{~mm}$, indicating from the perspective of the "alternation" of the drought-flood that the degree of drought-flood abrupt alternation is not as severe as the Qianxi County, which further proves the applicability and rationality of the indices. Therefore, the applicability of the revised DWAAI in Guizhou Province has been verified.

\section{Characteristics of temporal evolution}

\section{Distribution characteristics within a year}

As can be seen from Figure 4, the time of drought-flood abrupt alternation in Guizhou Province is mainly distributed from April to October, and the cumulative drought-flood abrupt alternations account for $93.51 \%$ of the total; from July to September, it's relatively concentrated with 75 times, 59 times and 67 times respectively, accounting for $19.48 \%, 15.32 \%$ and $17.40 \%$ of the total number of events, respectively.

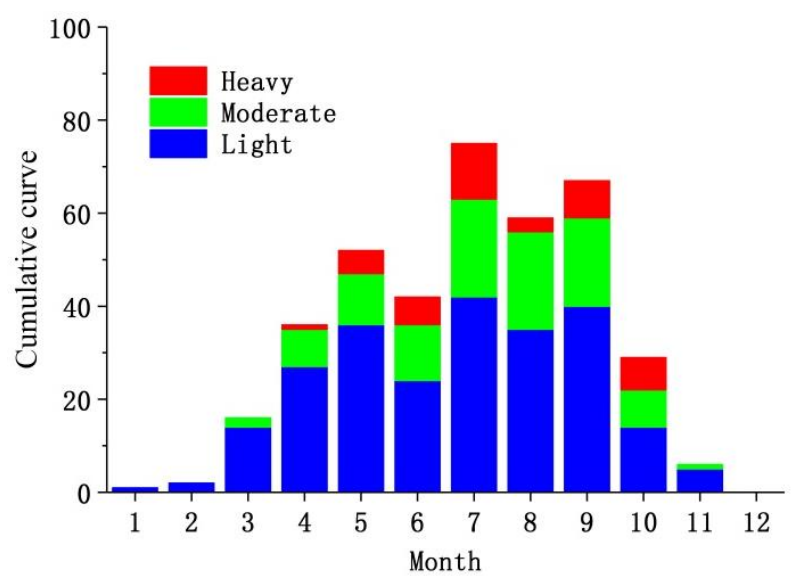

Figure 4. Annual distribution of drought-flood abrupt alternation events over 1968-2017 in Guizhou province 
From December to February of the following year, the drought-flood abrupt alternation rarely occurred; from the point of view of the cases of moderate and above drought-flood abrupt alternation, it mainly occurs from July to September, 33 times, 24 times and 27 times, accounting for $8.57 \%, 6.23 \%$ and $7.01 \%$ of the total times respectively, which is basically consistent with the research results by Chen et al. (2015) and $\mathrm{Lu}$ (2010) on the characteristics of drought, rainstorm and flood in Guizhou Province, respectively. The drought-prone type is summer drought and spring drought in Guizhou Province, and the rainfall is concentrated in May-October in the whole province, so the period from the end of spring to early autumn is the period of droughtflood abrupt alternation, which is consistent with the Figure 4, further proving the applicability of the DWAAI index in Guizhou Province.

\section{Interannual variation}

(1) Station proportion. As can be seen from Figure 5 , the station proportion of drought-flood abrupt alternation in Guizhou province fluctuates from $10.53 \%$ to $78.95 \%$ in recent 50 years with greater interannual difference. In 2015 and 1986, there were partially regional drought-flood abrupt alternations for 5 years; in 2013 and 2007, there were partially regional drought-flood abrupt alternations for 14 years; in 2016-2017 and 2014, there were regional drought-flood abrupt alternations for 21 years; in 2011-2012 and 2002, there were regional drought-flood abrupt alternations for 10 years; before 2000 , there were mainly partially regional and regional drought-flood abrupt alternation; after 2000, the regional drought-flood abrupt alternation occurred frequently, and the years with the highest station proportion were all after 2000, i.e., 2002 and 2011, respectively ( $78.95 \%$ of station proportion), which shows that the occurrence range of drought-flood abrupt alternation in recent 20 years is expanding.

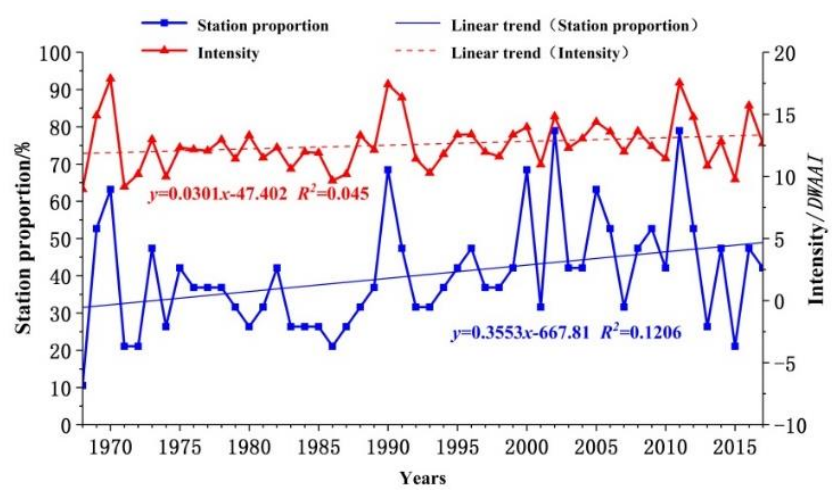

Figure 5. Variation characteristics of station proportion and intensity of drought-flood abrupt alternation over 1968-2017 in Guizhou province

(2) Intensity. As can be seen from Figure 5, the intensity of drought-flood abrupt alternation in Guizhou Province in recent 50 years fluctuated from 8.96 to 17.88 , and the average intensity of drought-flood abrupt alternation is 12.59 , which shows that the drought-flood abrupt alternation in Guizhou Province is mainly mild, and the intensity of drought-flood abrupt alternation is higher than 12.00 for 29 years, during which in 1970, 2011 and 1990, the intensity is higher than 17.00, that's, 17.88, 17.55 and 17.43, respectively. They are the three years with the highest intensity of drought-flood abrupt alternation over the past 50 years. 
From the change trend of station proportion and intensity (Table 2), the climate tendency rate is consistent with the result of Mann-Kendall method. The station proportion and intensity have increased in Guizhou Province in recent 50 years, and the increasing trend of station proportion is significant, which shows that with the increase of time, the intensity and range of drought-flood abrupt alternation in Guizhou Province increased.

Table 2. Trend detection results of station proportion and intensity of drought-flood abrupt alternation over 1968-2017 in Guizhou province

\begin{tabular}{c|c|c|c}
\hline & \multirow{2}{*}{ Linear tendency rate/10a-1 } & \multicolumn{2}{|c}{ Mann-Kendall test } \\
\cline { 3 - 4 } & & $\mathbf{Z}$ & $\boldsymbol{\beta}$ \\
\hline Station proportion/\% & $3.55^{*}$ & $2.06^{*}$ & 0.39 \\
Intensity & 0.3 & 1.4 & 0.04 \\
\hline
\end{tabular}

Note: $\mathrm{Z}$ is Statistics of Mann-Kendall test; $\beta$ is Sen's slope, means trend of annual average; * means significant trend when $\alpha=0.05$; the same below

\section{Characteristics of seasonal drought-flood abrupt alternation over the years}

(1) Spring (March-May). As can be seen from Figure 6a, the station proportion of drought-flood abrupt alternation in spring in Guizhou Province in the past 50 years ranged from $0.00 \%$ to $42.11 \%$, averaging $10.84 \%$; only in 1973 occurred the regional drought-flood abrupt alternation, with the station proportion of $42.11 \%$. In 1969, 1977, 1999 and 2006, there were partially regional drought-flood abrupt alternations or nonobvious drought-flood abrupt alternation for 4 years, while there were regional droughtflood abrupt alternations for the other 45 years, and large-scale drought-flood abrupt alternation occurred frequently from 1994 to 2007 in spring. The interannual intensity of drought-flood abrupt alternation in spring varies from 0.00 to 16.80, averaging 10.91; the intensity of drought-flood abrupt alternation in spring exceeded 12.00 for 15 years, of which it occurred after 2000 for 7 years and occurred for 4 years in recent 10 years, that's, 2009, 2011-2012 and 2016, respectively.

(2) Summer (June-August). As can be seen from Figure $6 b$, the station proportion of drought-flood abrupt alternation in summer in Guizhou Province over the past 50 years is between $0.00 \% \sim 57.89 \%$ (average $18.74 \%$ ), which is generally higher, indicating that the occurrence range of drought-flood abrupt alternation in summer is large in Guizhou Province. The years with the highest station proportion in summer is 2002, and the station proportion is $57.89 \%$, which is regional drought-flood abrupt alternation. In 1982, 1991, 2009 and 2012, there were regional drought-flood abrupt alternation for 4 years. In 2011 and 2005, there were partially regional drought-flood abrupt alternation for 10 years, and in 2016 and 2014, there were regional drought-flood abrupt alternation for 23 years. The interannual intensity of drought-flood abrupt alternation in spring varies from 0.00 to 27.02, averaging 13.74; the intensity of drought-flood abrupt alternation exceeded 12.00 for 37 years, of which it reached 27.02 in 2004, which is generally at a severe level, and it is the year with the strongest intensity of droughtflood abrupt alternation.

(3) Autumn (September-November). As can be seen from Figure 6c, the station proportion of drought-flood abrupt alternation in autumn for 50 years is between $0.00 \%$ and $47.37 \%$, averaging 10.63\%; in 1990 and 2011, there were regional drought-flood abrupt alternation in autumn for 2 years; in 1970, 1978 and 1996, there were partially 
regional drought-flood abrupt alternation in autumn for 3 years; in 1969 and 1975-1976, there were regional drought-flood abrupt alternation in autumn for 21 years, among which it occurred after 2000 for 9 years and after 2010 for 4 years.

The interannual intensity of drought-flood abrupt alternation in autumn varies from 0.00 to 19.36 , averaging 11.15; the intensity of drought-flood abrupt alternation in autumn exceeded 12.00 for 22 years, of which it reached 19.36 in 2011, which is generally at a moderate level, and it is the year with the strongest intensity of droughtflood abrupt alternation in autumn.

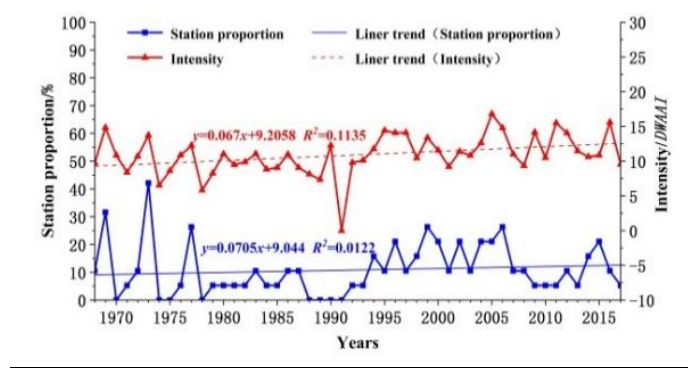

(a) Spring

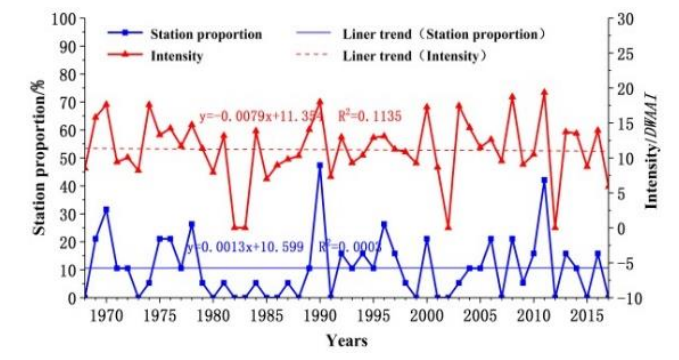

(c) Autumn

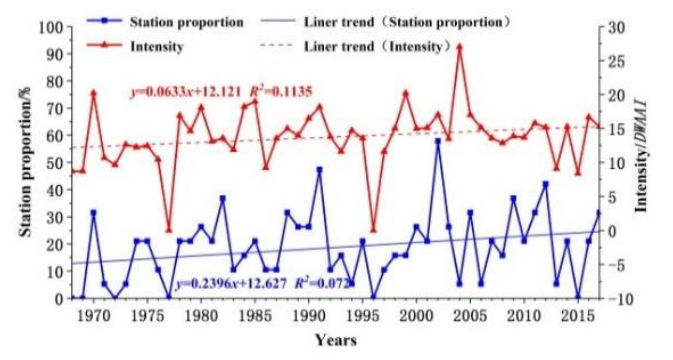

(b) Summer

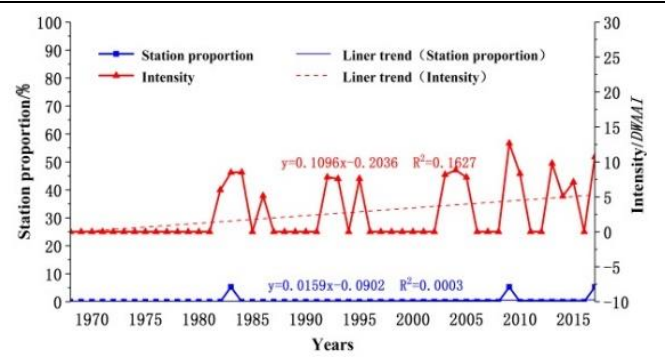

(d) Winter

Figure 6. The seasonal variation characteristics of station proportion and intensity of droughtflood abrupt alternation over 1968-2017 in Guizhou province

(4) Winter ((December-February). According to the calculation results, there were only three drought-flood abrupt alternation in winter in Guizhou Province in the past 50 years, which were in 1983, 2009 and 2017, and all of them were mild events. From Figure $6 \mathrm{~d}$, we cannot find the change rules from the station proportion. The interannual intensity of drought-flood abrupt alternation in winter ranges from 0.00 to 12.66 , averaging 2.59. Therefore, there is no obvious drought-flood abrupt alternation in winter in Guizhou Province.

According to the station proportion and intensity variation trend of drought-flood abrupt alternation in different seasons (Table 3), the climatic tendency rate is basically consistent with the result of Mann-Kendall method. In spring, the station proportion of drought-flood abrupt alternation in spring tends to increase slightly, and the intensity tends to increase significantly. The station proportion and intensity of drought-flood abrupt alternation increase significantly in summer. The intensity of drought-flood abrupt alternation in autumn tends to slightly decrease. The station proportion linear tendency rate isn't consistent with the result of the Mann-Kendall test statistic Z, but the absolute values of them are both lower, so there is no obvious change trend in station proportion in autumn; the station proportion and intensity of drought-flood abrupt alternation in winter increased, but not significantly. 


\section{Characteristics of spatial evolution}

\section{Spatial distribution characteristics of occurrence frequency}

As can be seen from Figure 7, the frequency of drought-flood abrupt alternation in Guizhou Province from 1968 to 2017 is obviously different, decreasing from east to west as a whole. The prone areas of drought-flood abrupt alternation are mainly concentrated in central and southern Tongren and southeastern, central and eastern Guizhou, with a frequency of $50.85 \% \sim 68.00 \%$, once every $1-2$ year; the frequency in the western part of Bijie is low, ranging from $24.01 \%$ to $33.90 \%$.

Table 3. Trend detection results of station proportion and intensity of drought-flood abrupt alternation on different seasons over 1968-2017 in Guizhou province

\begin{tabular}{c|c|c|c|c}
\hline \multirow{2}{*}{ Season } & & \multirow{2}{*}{ Linear tendency rate/10a-1 } & \multicolumn{2}{|c}{ Mann-Kendall test } \\
\cline { 3 - 5 } & & 0.71 & $\mathbf{Z}$ & $\boldsymbol{\beta}$ \\
\hline \multirow{2}{*}{ Spring } & Station proportion/\% & $0.67^{*}$ & 1.35 & 0 \\
& Intensity & $2.4^{*}$ & $2.11^{*}$ & 0.06 \\
\hline \multirow{2}{*}{ Summer } & Station proportion/\% & $0.63^{*}$ & $2.87^{*}$ & 0.25 \\
& Intensity & 0.01 & $1.97 *$ & 0.07 \\
\hline \multirow{2}{*}{ Autumn } & Station proportion/\% & -0.08 & -0.02 & 0 \\
& Intensity & 0.16 & -0.09 & -0.01 \\
\hline \multirow{2}{*}{ Winter } & Station proportion/\% & 1.1 & 0.4 & 0 \\
& Intensity & & 1.74 & 0 \\
\hline
\end{tabular}

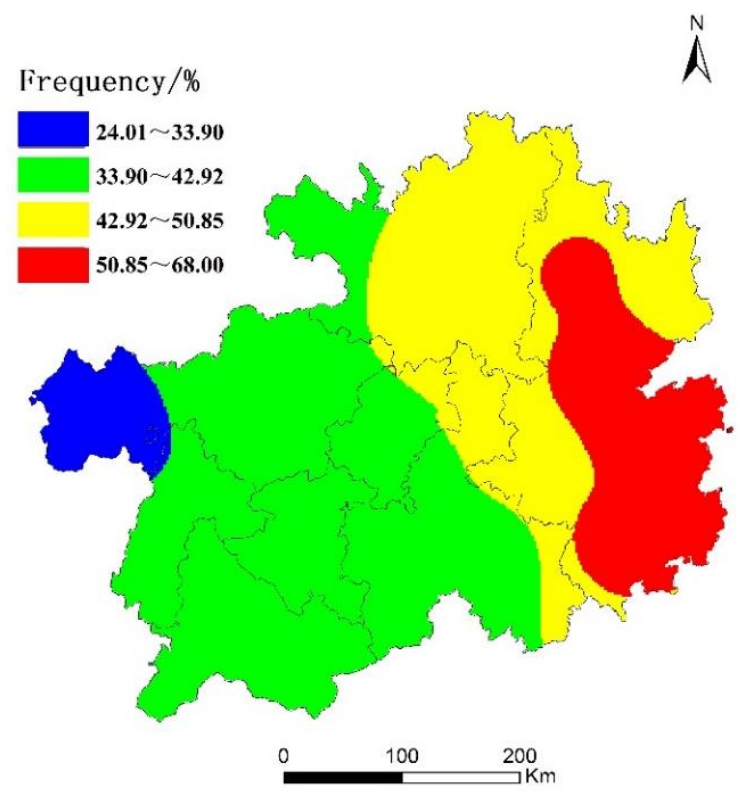

Figure 7. Spatial distribution of drought-flood abrupt alternation frequency over 1968-2017 in Guizhou province

\section{Characteristics of seasonal spatial variation}

In accordance with the calculation result, the frequency of drought-flood abrupt alternation in different seasons is calculated by four zones including once every more than 10 years $(0 \sim 10 \%)$, once every $7 \sim 10$ years $(10 \% \sim 15 \%)$, once every $5 \sim 7$ years 
$(15 \% \sim 20 \%)$ and once every less than 5 years (> 20\%), with the spatial distribution shown in Figure 7 and the area proportion of different zones shown in Table 4. The area proportion of each frequency and the product of the frequency are used to express the severity index of the zone with drought-flood abrupt alternation.

Table 4. The area proportion of each frequency on different seasons over 1968-2017 in Guizhou province (\%)

\begin{tabular}{c|c|c|c|c|c}
\hline Erequency & $0 \sim 10 \%$ & $10 \% \sim 15 \%$ & $15 \% \sim 20 \%$ & $>20 \%$ & Severity index \\
\hline Season & 48.43 & 31.97 & 17.47 & 2.13 & 9.90 \\
Spring & 3.53 & 21.25 & 21.44 & 53.78 & 17.34 \\
Summer & 38.79 & 41.65 & 19.56 & 0.00 & 10.57 \\
Autumn & 100.00 & 0.00 & 0.00 & 0.00 & 5.00 \\
Winter &
\end{tabular}

As can be seen from Figure 8, the spatial distribution of the frequency of droughtflood abrupt alternation varies greatly in different seasons.

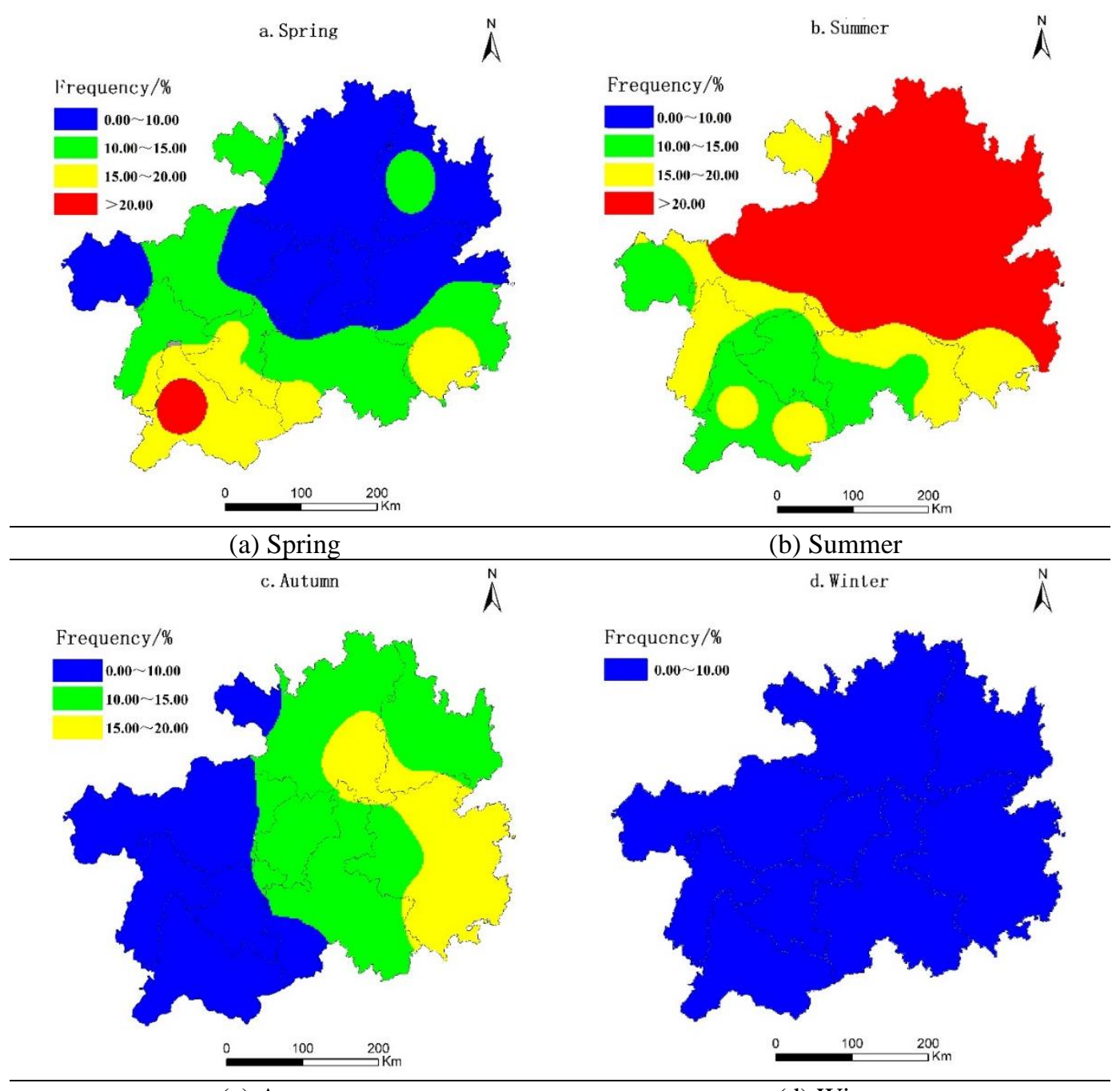

(c) Autumn

(d) Winter

Figure 8. Spatial distribution of drought-flood abrupt alternation frequency on different seasons over 1968-2017 in Guizhou province 
The frequency of drought-flood abrupt alternation in spring is higher in the south than in the north, and the prone area is mainly in the southwest of Guizhou, of which the frequency in Xingyi City is more than 20\%, that's, once every less than 5 years; the frequency in most of the central and northern regions and the western part of Bijie is less than $10 \%$ (Figure $8 a$ ). Summer is the opposite to spring, with the overall decline from north to south, the prone areas with the frequency of more than $20 \%$ run throughout most of the north-central region, and only in the southwest of Guizhou, the frequency is less than 10\% (Figure $8 b$ ). In autumn, the frequency of drought-flood abrupt alternation decreases from east to west, and the southeast of Guizhou, the southwest of Tongren and the southeast of Zunyi are relatively vulnerable to droughtflood abrupt alternation, with the frequency of $15 \% \sim 20 \%$, that's, the frequency in most areas of northwest and southwest Guizhou is less than $10 \%$ (Figure $8 c$ ). Fewer droughtflood abrupt alternation occurs in winter, without obvious characteristics of the spatial distribution, and the frequency is below $10 \%$ in the whole province (Figure $8 d$ ).

From Table 4, it can be seen that the frequency of drought-flood abrupt alternation in more than $80 \%$ areas of the province in spring and autumn is less than 15\%; the frequency of drought-flood abrupt alternation in summer is over 50\% in more than $50 \%$ of the whole province, and only $3.53 \%$ of the area have the frequency of lower than $10 \%$. In winter, there are less drought-flood abrupt alternation events. In terms of severity, drought-flood abrupt alternation is the severest in summer, with the order from high to low as summer, autumn, spring and winter.

\section{Characteristics of interdecadal spatial change}

In order to describe the characteristics of interdecadal change conveniently, every 10 years has been counted as one decade since 1968. In accordance with the calculation result, the frequency of drought-flood abrupt alternation in different decades is calculated by four zones including once every 5 years $(0 \sim 20 \%)$, once every $3 \sim 5$ years $(20 \% \sim 33.33 \%)$, once every $2 \sim 3$ years $(33.33 \% \sim 50 \%)$ and once every $1 \sim 2$ years (>50\%), with the spatial distribution shown in Figure 8, and the area ratios of different zones shown in Table 5.

Table 5. The area proportion of each frequency in different decades in Guizhou province(\%)

\begin{tabular}{c|c|c|c|c|c}
\hline Erequency & $0 \sim 20 \%$ & $20 \% \sim 33.33 \%$ & $33.33 \% \sim 50 \%$ & $>50 \%$ & Severity index \\
\hline Decade & 2.39 & 33.78 & 60.37 & 3.46 & 36.13 \\
\hline $1968-1977$ & 13.79 & 35.48 & 47.79 & 2.94 & 32.22 \\
\hline $1978-1987$ & 4.31 & 8.16 & 49.05 & 38.48 & 42.29 \\
\hline $1988-1997$ & 0.00 & 0.45 & 48.62 & 50.94 & 45.84 \\
\hline $1998-2007$ & 1.38 & 5.14 & 58.45 & 35.02 & 43.38 \\
\hline $2008-2017$ & & & &
\end{tabular}

As can be seen from Figure 9, except for 1998-2007, the spatial distribution of drought-flood abrupt alternation in each decade basically declines from east to west. With the increase of the decades, the scope of prone areas has been expanding. From 1968 to 1987 , the frequency is higher than $50 \%$, i.e. once every 1-2 years, the droughtflood abrupt alternation is sporadically distributed in southeast Quizhou, Bijie, Zunyi and Tongren (Figures 9a,b). From 1988 to 1997, the scope of prone areas has been extended to Guiyang, Zunyi, Tongren and southeast Quizhou (Figure 9c). From 1998 to 2007, except for some areas in Anshun, the drought-flood abrupt alternation occurred 
once every $1 \sim 3$ years in the whole province, among which, the scope of the prone areas once every $1 \sim 2$ years was further expanded to the northwest, southwest and southeast Guizhou (Figure 9d). From 2008 to 2017, except for some areas in Zunyi and southwest Guizhou, the drought-flood abrupt alternation occurred once every 1-3 years in the whole province, and the range of prone areas was slightly reduced compared with that in 1998-2007. However, the overall distribution range is still relatively large (Figure 9e).

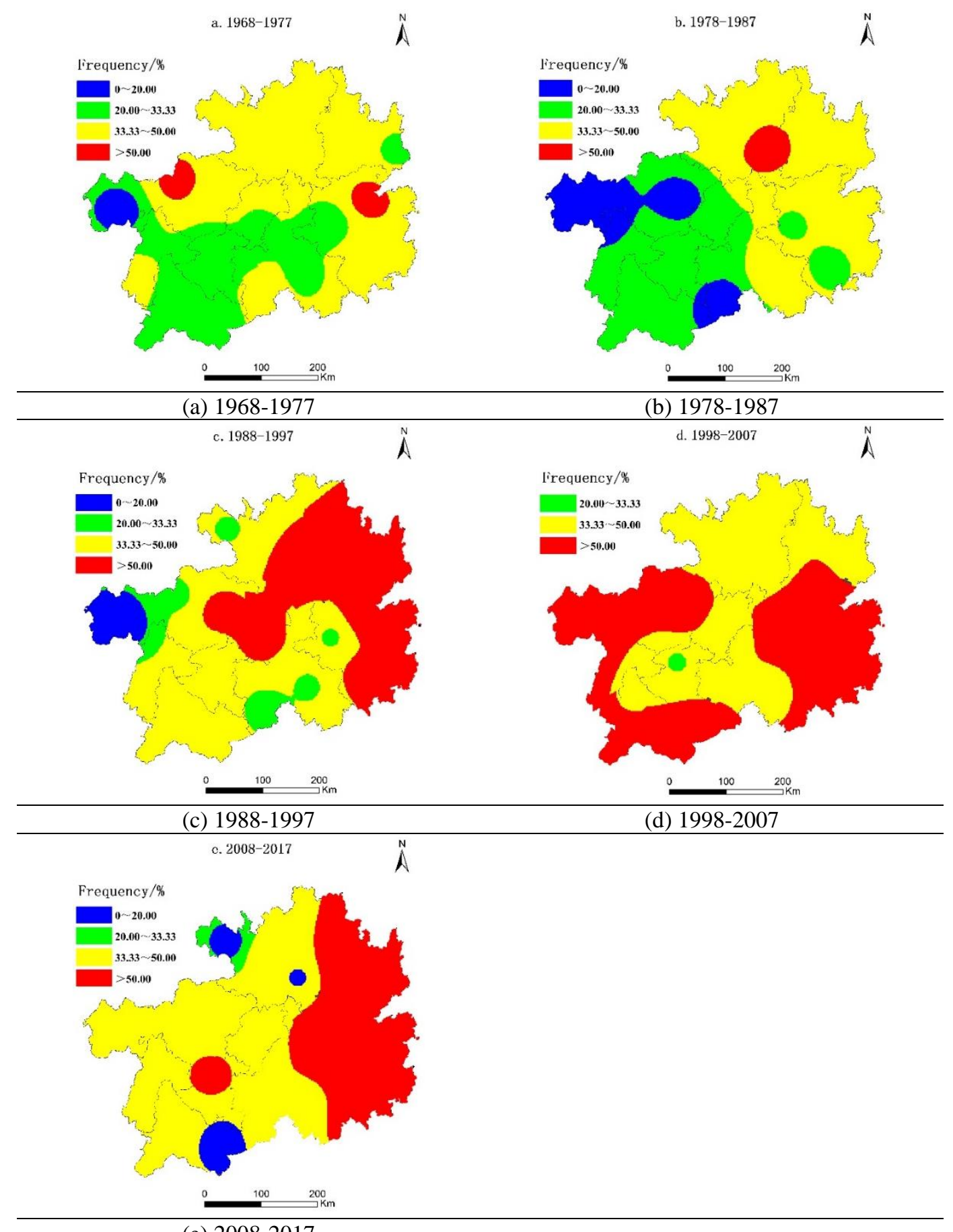

(e) 2008-2017

Figure 9. Spatial distribution of drought-flood abrupt alternation frequency in different decades in Guizhou province 
As can be seen from Table 5, from 1988 to 1997, the area of the prone areas with drought-flood abrupt alternation once every 1-2 years increases sharply. In 1998-2007, more than $50 \%$ of the area of the province suffered from drought-flood abrupt alternation once every 1-2 years. In recent 10 years, the area of prone areas has decreased, and the frequency is $33 \% \sim 50 \%$, that's, the area with drought-flood abrupt alternation once every $2 \sim 3$ years is relatively stable. The frequency of drought-flood abrupt alternation is $20 \% \sim 33.33 \%$, that's, the area with drought-flood abrupt alternation once every $3 \sim 5$ years decreased significantly. In terms of severity, from 1998 to 2007, the drought-flood abrupt alternation is the severest, followed by it from 2008 to 2017 and it is the lowest from 1978 to 1987.

\section{Discussion}

Chen et al. (2015) studied the temporal and spatial variation characteristics of drought in Guizhou Province. Lu (2010) carried out research in the climate characteristics of rainstorms and floods in Guizhou Province, and concluded that spring and summer are the high incidence periods of drought in Guizhou Province, the spring drought tends to occur in the western region of Guizhou, and the summer drought tends to occur in the northeastern region of Guizhou, from late-December to early-February, there is no rainstorm in the whole province, from mid-November to mid-March, there is no heavy rainstorm, and the extraordinary rainstorm concentrates from late-May to midSeptember, which is consistent with the spatial and temporal characteristics of droughtflood abrupt alternation in the search results of this paper. Compared with 1998-2007, although the range in the recent 10 years is slightly reduced, high-intensity drought and flood abrupt alternation occurs more frequently, such as in 2011 2012, 2014 and 2016, and the resulted social and economic losses are much higher than in the past, which indicates that the drought -flood abrupt alternation has a tendency of becoming more intense. Therefore, it's of important practical significance to study the evolution law of drought and flood abrupt alternation, monitor it and alarm early warnings.

The drought in earlier period is the premise of the formation of drought-flood abrupt alternation, and the extreme precipitation event is a necessary condition for drought and flood abrupt alternation. Raksekhar et al. (2015), Liu et al. (2014) assessed or analyzed the drought characteristics of the study area by establishing or improving drought indicators. Goswami et al. (2018), Andrea et al. (2018) studied the formation factors of extreme precipitation. Compared with the above research results, the DWAAI can couple "droughts" and "floods", and describe the entire process of drought-flood abrupt alternation events completely, which has laid a foundation for exploring the formation mechanism of drought-flood abrupt alternation events.

The food crops and economic crops in Guizhou are mainly harvested in the autumn, and the crucial growth period of most crops coincides with the period of the occurrence of drought-flood abrupt alternation, therefore, the drought-flood abrupt alternation has a great impact on agricultural production. And the influencing mechanism of droughtflood abrupt alternation on crops is quite complicated, generally speaking, both droughts and floods would affect the growth and development of crops and thus leading to production reduction. In addition, if drought-d flood abrupt alternation occurs, it would produce superposed losses; but for some dryland crops, a certain-degree drought during the rooting period can effectively increase the root length and thus enhancing the drought tolerance; if the drought is relieved or there is a slight flood, there may be a 
certain "compensation" effect (Gao et al., 2017). Therefore, it is necessary to combine specific physiological indicators of crops and the soil moisture conditions to carry out more in-depth experimental research on the crops' response mechanism to the abrupt alternation of droughts and floods.

\section{Conclusions}

(1) The revised DWAAI index has the advantages of high accuracy, comprehensive reflection, reasonable calculation results and good agreement with the real situation, so it has a good applicability in Guizhou Province.

(2) Temporally, the drought-flood abrupt alternation mainly occurs from April to October in Guizhou Province. In terms of interannual variation, the station proportion and intensity have the trend of increasing year by year, and the increasing trend of station proportion is significant. In terms of seasonal characteristic, except autumn, the station proportion and intensity all have an increasing trend, among which the intensity of drought-flood abrupt alternation in spring and summer and the station proportion of drought-flood abrupt alternation in summer increase obviously, the intensity of droughtflood abrupt alternation in autumn has a decreasing trend and the trend of station proportion is not obvious.

(3) Spatially, the frequency of drought-flood abrupt alternation in Guizhou Province is decreasing from east to west, varying greatly in different seasons, i.e., in the southern region in spring, in the middle and north in summer with the largest area of the prone areas, and in the eastern region in autumn. Along with the increase of the decades, the scope of the areas where drought and waterlogging change rapidly is expanding, among which the drought-flood abrupt alternation is the severest from 1998 to 2007.

(4) The spatial and temporal characteristics of drought-flood abrupt alternation events could be discussed by improving the index. In the future research, on the one hand, we can try to combine atmospheric circulation and other factors to study the formation mechanism of the drought-flood abrupt alternation events, so as to better predict and give warning; on the other hand, we can use modeling, experimentation and other approaches to study the influencing mechanism of drought-flood abrupt alternation on certain crops, such as rice, corn or wheat, so as to develop scientific countermeasures for disaster prevention and alleviation.

Acknowledgements. This paper is supported by General Project of National Natural Science Foundation of China (51779093); Science and Technology Project of Water Resources Department of Guizhou Province (KT201705); Scientific Research Project of Public Welfare Industry of Ministry of Water Resources (201301039); Innovation fund for doctoral students of North China University of Water Resources and Electric Power.

\section{REFERENCES}

[1] Chen, X. K., Xu, J. X., Lei, H. J., Hu, J. P., Zhang, Z. Z., Huang, X., Shang, C, J., Yang, J. (2015): Spatial and temporal distribution characteristics of drought and its regional response to climate change in Guizhou Province. - Journal of Irrigation and Drainage 34(8): 74-81. 
[2] Cheng, Z., Xu, M., Luo, L. S., Ding, X. J. (2012): Climate Characteristics of Droughtflood Abrupt Change Events in Huaihe River Basin. - Journal of China Hydrology 32(1): 73-79.

[3] Dittus, A. J., Karoly, D. J., Donat, M. G. (2018): Alexander. Understanding the role of sea surface temperature-forcing for variability in global temperature and precipitation extremes. - Weather and Climate Extremes 21(9): 1-9.

[4] Djebou, D. C. S., Singh, V. P., Frauenfeld, O. W. (2014): Analysis of watershed topography effects on summer precipitation variability in the southwestern United States. - Journal of Hydrology 511: 838-849.

[5] Gao, Y., Hu, T. S., Yuan, H. W., Yang, J. W. (2017): Analysis on yield reduced law of rice in Huaibei plain underdrought-flood abrupt alternation. - Transactions of the Chinese Society of Agricultural Engineering 33(21): 128-136.

[6] Goswami, P. U., Hazra, B., Goyal, K. M. (2018): Copula-based probabilistic characterization of precipitation extremes over north sikkim himalaya. - Atmospheric Research 212: 273-284.

[7] Grinsted, A., Moore, J. C., Jevrejeva, S. (2014): Application of the cross wavelet transform and wavelet coherenceto geophysical time series. - Nonlinear Processes in Geophysics 11(5/6): 561-566.

[8] Han, D. M., Yang, G. Y., Yan, D. H. (2014): Spatial-temporal Feature Analysis of Drought and Flood in Northeast China in Recent 50 Years. - Water Resources and Power 32(6): 5-8.

[9] Huang, W. H., Yang, X. G., Li, M. S., Zhang, X. Y., Wang, M. T., Dai, Z. W., Ma, J. H. (2010): Evolution characteristics of seasonal drought in the south of China during the past 58 years based on standardized precipitation index. - Transactions of the Chinese Society of Agricultural Engineering 26(7): 50-59.

[10] Huang, R. (2015): Research on evolution and Countermeasures of drought-floods abrupt alternation events in Huaihe River basin. - China Institute of Water Resources \& Hydropower Research.

[11] Langousis, A., Kaleris, V. (2014): Statistical framework to simulate daily rainfall series conditional on upper- air predictor variables. - Water Resources Research 50(5): 39073932.

[12] Liu, Z. Y., Zhang, J. P., Luo, H. X., He, Y. K. (2014): Temporal and spatial distribution of maize drought in Southwest of China based on agricultural reference index for drought. - Transactions of the Chinese Society of Agricultural Engineering 30(2): 105-115.

[13] Lu, E. (2009): Determining the start, duration, and strength of flood and drought with daily precipitation: Rationale. - Geophysical Research Letters 36: L12707.

[14] Lu, R. J. (2010): Analysis of Climate Characteristic of Rainstorm in Guizhou Province. Lanzhou University.

[15] Maheras, P., Xoplaki, E., Kutiel, H. (1999): Wet and Dry Monthly Anomalies Across the Mediterranean Basin and Their Relationship with Circulation, 1860-1990. - Theoretical Applied Climatology 64: 189-199.

[16] Raksekhar, D., Singh, V. P., Mishra, A. K. (2015): Multivariate drought index: An information theory based approach for integrated drought assessment. - Journal of Hydrology 526(11/12): 164-182.

[17] Shan, L. J., Zhang, L. P., Zhang, Y. J., She, D. X., Xia, J. (2018): Characteristics of drywet abrupt alternation events in the middle and lower reaches of the Yangtze River Basin and their relationship with ENSO. - Acta Geographica Sinica 37(1): 25-40.

[18] Shen, B. Z., Zhang, S. X., Yang, H. W., Wang, K., Feng, G. L. (2012): Analysis of characteristics of a sharp turn from drought to flood in the middle and lower reaches of the Yangtze River in spring and summer in 2011. - Acta Physica Sinica 61(10): 530-540.

[19] Wu, Z. W., Li, J. P., He, J. H., Wang, Z. H. (2006a): Large-scale Atmospheric Circulation Anomaly and Long Period of Drought and Flood Abrupt Alternation in the Middle and 
Lower Reaches of the Yangtze River in Summer. - Chinese Science Bulletin 51(14): $1717-1724$.

[20] Wu, Z., Li, J., He, J. (2006b): Occurrence of droughts and floods during the normal summer monsoons in the mid and lower reaches of the Yangtze River. - Geophysical Research Letters 33(5): 813-816.

[21] Zhang, S. F., Zhang, J. C., Min, J. J., Zhang, Z. X., Zhuang, J. Y., Lin, J. (2012): Drought-flood abrupt alternation based on runoff in the Huaihe River Basin during rainy season. - Journal of Lake Sciences 24(5): 679-686.

[22] Zhou, Y., Li, N., Ji, Z. H., Gu, X. T., Fan, B. H. (2013): Temporal and Spatial Patterns of Droughts Based on Standard Precipitation Index (SPI) in Inner Mongolia during 19812010. - Journal of Natural Resources 28(10): 1694-1706. 